RESEARCH REPORT

\title{
Increase of regional total cancer incidence in north Sweden due to the Chernobyl accident?
}

\author{
Martin Tondel, Peter Hjalmarsson, Lennart Hardell, Göran Carlsson, Olav Axelson
}

J Epidemiol Community Health 2004;58:1011-1016. doi: 10.1136/jech.2003.017988

\begin{abstract}
See end of article for authors' affiliations

.....................

Correspondence to: Dr M Tondel, Division of Occupational and Environmental Medicine, Department of Molecular and Clinical Medicine, Faculty of Health Sciences, Linköping University, 581 85 Linköping, Sweden; Martin.Tondel@lio.se
\end{abstract}

Accepted for publication 24 February 2004

\begin{abstract}
Study objective: Is there any epidemiologically visible influence on the cancer incidence after the Chernobyl fallout in Sweden?

Design: A cohort study was focused on the fallout of caesium-137 in relation to cancer incidence 19881996.

Setting: In northern Sweden, affected by the Chernobyl accident in 1986, 450 parishes were categorised by caesium-137 deposition: <3 (reference), 3-29, 30-39, 40-59, 60-79, and 80-120 kiloBecquerel/ $\mathrm{m}^{2}$.

Participants: All people 0-60 years living in these parishes in 1986 to 1987 were identified and enrolled in a cohort of 1143182 persons. In the follow up 22409 incident cancer cases were retrieved in 19881996. A further analysis focused on the secular trend.

Main results: Taking age and population density as confounding factors, and lung cancer incidence in 1988-1996 and total cancer incidence in 1986-1987 by municipality as proxy confounders for smoking and time trends, respectively, the adjusted relative risks for the deposition categories were 1.00 (reference $<3$ kiloBecquerel $\left./ \mathrm{m}^{2}\right), 1.05,1.03,1.08,1.10$, and 1.21 . The excess relative risk was 0.11 per $100 \mathrm{kiloBecquerel} / \mathrm{m}^{2}$ (95\% Cl 0.03 to 0.20$)$. Considering the secular trend, directly age standardised cancer incidence rate differences per 100000 person years between 1988 to 1996 and the reference period 1986-1987, were 30.3 (indicating a time trend in the reference category), 36.8, 42.0, 45.8, 50.1, and 56.4. No clear excess occurred for leukaemia or thyroid cancer.

Conclusions: Unless attributable to chance or remaining uncontrolled confounding, a slight exposure related increase in total cancer incidence has occurred in northern Sweden after the Chernobyl accident.
\end{abstract}

la Europe concerns about the consequences of the Chernobyl accident have focused on childhood malignancies, especially leukaemia, assumed to have a short latency period after irradiation. Several studies have been performed outside the former Soviet Union, but none has shown any clear relation with the fallout from the Chernobyl accident. ${ }^{1-5}$ These studies have follow up periods of up to six years. In Belarus, Ukraine, and the western part of Russia, there has been a dramatic increase in thyroid cancer incidence in children, but not leukaemia, in relation to the accident. ${ }^{6}$

Here we investigate whether the air borne ionising radiation that reached Sweden after the Chernobyl nuclear power plant accident in Ukraine could have influenced the cancer incidence. Five per cent of the released caesium-137 was deposited in Sweden due to heavy rainfall on 28-29 April 1986, mainly in the eastern coastal regions from Umeå in the north to Stockholm in the south. ${ }^{7}$ During the first weeks the main contributors to the dose rate were short lived nuclides replaced by long lived caesium-134 and caesium-137 isotopes. ${ }^{8}$ The effective dose to the inhabitants, depending on place of residence, outdoor activity, and dietary habits, ranged from $1-2 \mathrm{mSv}$ to a maximum of about $4 \mathrm{mSv}$ in the first year, with some $20 \%$ of the dose for a 50 year period received during the first two years. ${ }^{8}$

Our investigation is a cohort that includes the population of seven counties with the highest fallout, all in northern Sweden. There were also unaffected areas in these counties serving as internal reference areas. The south of Sweden was excluded as much less affected by the fallout, but also because of higher background cancer incidence rates, especially in the largest cities.

\section{METHODS}

Out of Sweden's 21 counties, the seven counties included in this study were Norrbotten, Västerbotten, Jämtland, Västernorrland, Gävleborg, Västmanland, and Uppsala County; these counties and some major cities are shown in figure 1. All people who were 0-60 years old in 1986 and who had the same address both on 31 December 1985 and 31 December 1987 were included in a cohort that was created on our request by the National Archives. This authority maintains a chronological registry, updated on 31 December by Statistics Sweden. Cancer cases and deaths in the cohort along with date of diagnosis were retrieved from the Swedish Cancer Registry for 1986 to 1996. If there was more than one malignant neoplasm registered for a person, we considered only the first one. All neoplasms were coded according to the International Classification of Diseases (ICD), version 7, as continuously used by the Swedish Cancer Registry. A short latency was allowed for as the follow up period started on 1 January 1988 when the cohort included 1143182 persons with information on age, sex, and parish of residence during the two preceding years. Table 1 gives the number of cancer cases and deaths during the follow up 1988-1996.

To meet the requirement of informed consent, the responsible authority, the Swedish Data Inspection Board, accepted advertising of the study in the two largest national newspapers. Subsequently there was a follow up by articles in the local press and interviews in radio and television. There were no refusals, as described in some detail elsewhere. ${ }^{9}$

By assignment with the Swedish Radiation Protection Authority, the Geological Survey of Sweden had performed aerial gamma measurements over the whole of Sweden from 


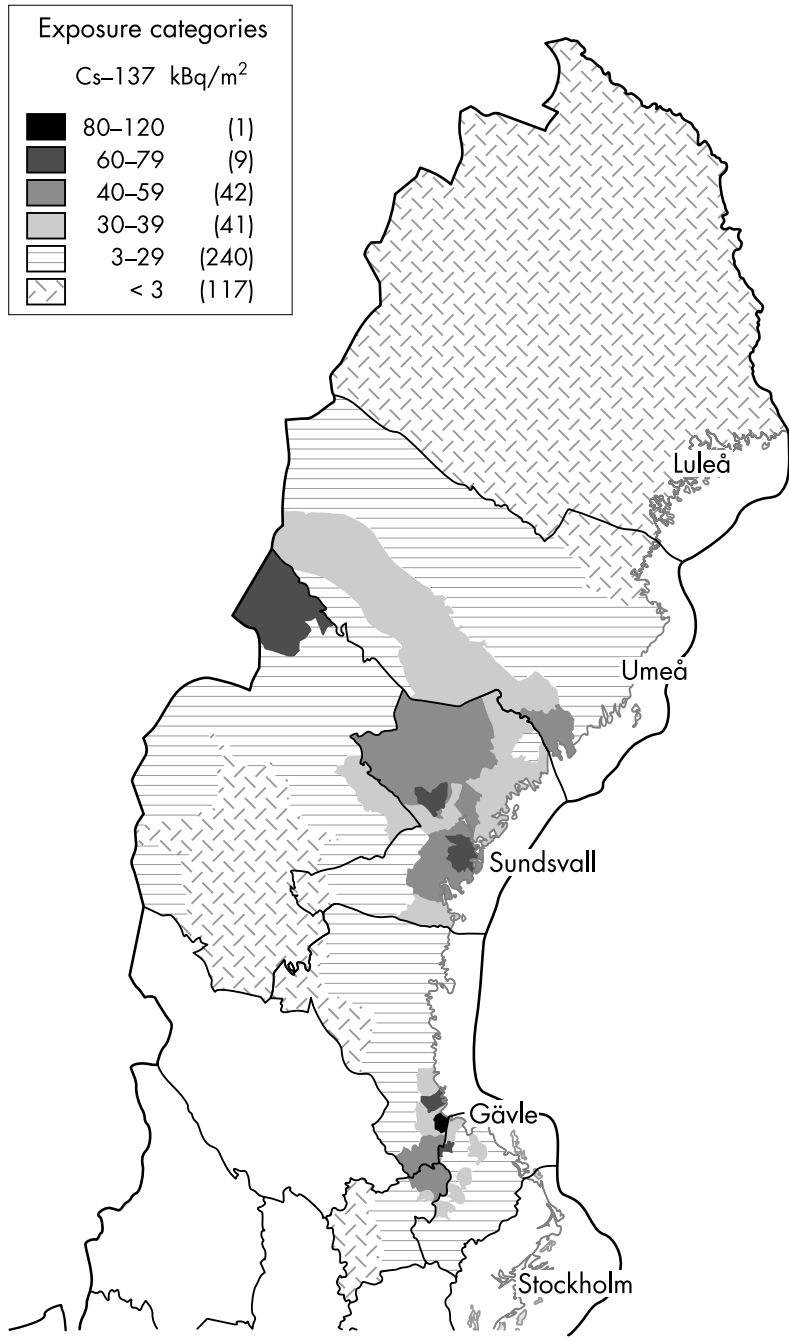

Figure 1 Parishes in the study area classified by ground deposition of caesium-137 and number of parishes in parentheses for each category. The map was originally produced by the Geological Survey of Sweden on behalf of the Swedish Radiation Protection Authority, here modified after permission from the latter.

May to October 1986 resulting in a ground deposition map of caesium-137 in 12 different categories. Collapsing these categories, the population in the 450 parishes-that is, the smallest administrative units of these seven counties-were classified into six exposure categories: <3, 3-29, 30-39, 40$59,60-79$, and $80-120 \mathrm{kiloBecquerel} / \mathrm{m}^{2}$ (fig $\mathrm{l}$ and table 1 ). The 117 parishes not affected $\left(<3 \mathrm{kiloBecquerel} / \mathrm{m}^{2}\right)$ in these counties served as reference areas. The parishes were classified before any epidemiological analyses and to maximise the contrast in deposition of caesium-137.
As cancer risks tend to correlate with population density, we controlled for this potential confounding effect by two models. One model was based on the number of individuals $/ \mathrm{km}^{2}$ in each parish. The other model involved the official classification by Statistics Sweden in so called homogeneity regions that classify municipalities in Sweden into six categories depending on the population density, and the number of inhabitants in the nearest vicinity of the main city in that municipality. ${ }^{10}$ Both classifications were associated with cancer incidence as well as with the exposure categories, thus confirming an a priori suspected confounding effect (tables 2 and 3). There was a slight difference in the risk estimates indicating that the two classifications had somewhat different relations to cancer incidence, and therefore both were included in the analysis.

To account for smoking habits, industrial and environmental exposures and ill defined other risk factors, usually subsumed as socioeconomic risk factors, the age standardised lung cancer (ICD 7, 162.1) incidence by the municipality for the period 1988-1996 was taken as a proxy indicator for this aggregate of risk factors. The lung cancer proxy exerted positive confounding only in the highest exposure category. Similarly, all cancer in 1986-1987 (that is, before any expected effect of the fallout) was considered a proxy determinant for cancer incidence in the follow up period and was also found to be a weak positive confounder in all exposure categories. We stratified both lung cancer incidence 1988-1996 and total cancer incidence 1986-1987 into four equally large groups based on the number of included municipalities (table 2). Finally, we used the classification suggested by Dreyer et al for studying the distribution of cancers related to tobacco smoking and the different fallout categories, calculating age adjusted incidence rate ratios (table 4). ${ }^{11}$ In these calculations we neglected, for simplicity, the other adjustment variables applied in table 3, as they were found to have had only a weak influence on the rates.

In the first analysis we followed up each person over time and calculated the number of person years from 1 January 1988 until 31 December 1996, or until the occurrence of the first malignant neoplasm or death, whichever came first (tables 3 and 4). Throughout all the analyses, five year age groups were applied. Mantel-Haenszel weighted risk estimates were calculated (tables 2-4), and a log-linear Poisson regression model with maximum likelihood estimates was applied for the trend analyses (table 3 and 4).

In the second analysis regarding the secular trend an age restriction was necessary to obtain the same age distribution both at starting of the cohort and at the end of follow up in 1996- that is, comparable incidence rates over time. In tables 5-7 the cancer incidences per 100000 person years were directly standardised for age using weights corresponding to the European population, as defined by the World Health Organisation, but restricted to the age span 5-59 years. ${ }^{12}$

Both first and second analyses were performed in Stata Statistical Software, release 6.0 (Stata Corporation, College Station, TX).

Table 1 Number of people, cancer cases, and deaths for men and women by exposure category

\begin{tabular}{|c|c|c|c|c|c|c|c|c|c|}
\hline \multirow{2}{*}{$\begin{array}{l}\text { Exposure category } \mathrm{kBq} \\
\mathrm{Cs}-137 / \mathrm{m}^{2}\end{array}$} & \multicolumn{3}{|c|}{ Population 1988} & \multicolumn{3}{|c|}{ Number of cancer cases 1988-1996 } & \multicolumn{3}{|c|}{ Number of all deaths 1988-1996 } \\
\hline & Men & Women & Total & Men & Women & Total & Men & Women & Total \\
\hline$<3$ & 185646 & 173863 & 359509 & 2810 & 3881 & 6691 & 5629 & 3029 & 8658 \\
\hline $3-29$ & 269922 & 257890 & 527812 & 4501 & 5877 & 10378 & 7294 & 4358 & 11652 \\
\hline $30-39$ & 48053 & 44270 & 92323 & 752 & 1075 & 1827 & 1294 & 811 & 2105 \\
\hline $40-59$ & 63512 & 61350 & 124862 & 1185 & 1559 & 2744 & 2048 & 1188 & 3236 \\
\hline $60-79$ & 11112 & 10513 & 21625 & 172 & 229 & 401 & 291 & 172 & 463 \\
\hline $80-120$ & 8722 & 8329 & 17051 & 153 & 215 & 368 & 288 & 159 & 447 \\
\hline Total & 586967 & 556215 & 1143182 & 9573 & 12836 & 22409 & 16844 & 9717 & 26561 \\
\hline
\end{tabular}


Table 2 (A-D) Strength of four identified risk factors for the total cancer outcome 1988-1996. Mantel-Haenszel weighted incidence rate ratios (MH-IRR) as adjusted by age with $95 \%$ confidence intervals $(95 \% \mathrm{CI})$. Homogeneity regions (H region) go from sparse $(\mathrm{H} 6)$ to dense $(\mathrm{H} 3)$ populated regions. Lung cancer incidence 1988-1996 was taken as a proxy determinant for an aggregate of risk factors, including smoking, and similarly, the total cancer incidence 1986-1987 was taken as a determinant for total cancer incidence 1988-1996

\begin{tabular}{|c|c|c|c|c|c|c|c|c|c|c|c|}
\hline \multicolumn{3}{|c|}{ (A) Population density } & \multicolumn{3}{|c|}{ (B) $\mathrm{H}$ region } & \multicolumn{3}{|c|}{ (C) Lung cancer incidence 1988-1996 } & \multicolumn{3}{|c|}{ (D) All cancer incidence 1986-1987 } \\
\hline Density* & Cases (n) & MH-IRR $(95 \% \mathrm{Cl})$ & $\mathrm{H}$ region $\dagger$ & Cases (n) & MH-IRR $(95 \% \mathrm{CI})$ & Lung cancerł & Cases (n) & MH-IRR $(95 \% \mathrm{CI})$ & All cancer§ & Cases (n) & MH-IRR $(95 \% \mathrm{Cl})$ \\
\hline$<40$ & 11699 & 1.00 & H6 & 4969 & 1.00 & $\leqslant 7.99$ & 2119 & 1.00 & $<82$ & 2680 & 1.00 \\
\hline $40-199$ & 4792 & 1.09 (1.05 to 1.13$)$ & H5 & 4911 & 1.03 (0.99 to 1.08$)$ & $8.00-9.99$ & 5567 & $1.00(0.95$ to 1.06$)$ & $82-106$ & 5937 & $1.08(1.02$ to 1.13$)$ \\
\hline $200-499$ & 3771 & 1.09 (1.05 to 1.13 ) & $\mathrm{H} 4$ & 1864 & $1.03(0.97$ to 1.09$)$ & $10.00-11.99$ & 8745 & $1.04(0.99$ to 1.10$)$ & $107-122$ & 7136 & $1.05(1.00$ to 1.11$)$ \\
\hline$\geqslant 500$ & 2147 & 1.10 (1.05 to 1.16$)$ & H3 & 10665 & $1.09(1.05$ to 1.14$)$ & $\geqslant 12.00$ & 5978 & 1.05 (1.00 to 1.11$)$ & $\geqslant 123$ & 6656 & $1.11(1.06$ to 1.17$)$ \\
\hline Total & 22409 & & & 22409 & & & 22409 & & & 22409 & \\
\hline
\end{tabular}

*Number of people per $\mathrm{km}^{2}$ on parish level. †Population density classified by Statistics Sweden on municipality level. flung cancer incidence per 100000 person years $1988-1996$ on municipality level. §All sites cancer incidence for ages 5-59 years per 100000 person years 1986-1987 on municipality level.

\section{RESULTS}

The age adjusted relative risk for all cancer sites showed in the first step analyses a slight increase in all exposure categories, using $<3$ kiloBecquerel caesium- $137 / \mathrm{m}^{2}$ as the internal reference, except for category 60-79 kiloBecquerel/ $\mathrm{m}^{2}$ (table 3, first column). With adjustment for other factors, this pattern remained except when all of them were taken into account in Mantel-Haenszel weighted relative risk estimates. Women had an age adjusted relative risk of 1.34 compared with men, and there was no confounding effect by sex as the distribution of men and women was the same in the various exposure categories (table 1). Furthermore, it is obvious from table 4, that sex does not exert a confounding effect as the sex adjusted risk estimates are identical with the unadjusted ones.

Because the specific combination of all risk factors in the highest exposure category (last column table 3 ) was not represented in the reference category $(<3$ kiloBecquerel caesium $-137 / \mathrm{m}^{2}$ ), the reference had to be the second category (3-29 kiloBecquerel $/ \mathrm{m}^{2}$ ), where this combination could be found. When a Poisson regression, instead of the MantelHaenszel incidence rate ratios, was applied for the fully adjusted model in last column, table 3, the relative risk estimates obtained for each exposure category were 1.00 (reference, $<3 \mathrm{kiloBecquerel} / \mathrm{m}^{2}$ ), 1.06 (95\% CI 1.02 to 1.10 ), 1.06 ( 0.99 to 1.12$), 1.07$ ( 1.01 to 1.14$), 1.00$ (0.86 to 1.12 ), and 1.16 (0.98 to 1.37$)$ - that is, the results were similar with both methods. Using this regression and taking the midpoint in each interval as the exposure level, the cancer risk could be expressed as an excess relative risk of 0.11 per $100 \mathrm{kiloBecquerel} / \mathrm{m}^{2}$ (95\% CI 0.03 to 0.20 ).

Regarding cancers with and without relation to smoking, there was a significantly increased relative risk by exposure categories irrespective of this relation (table 4). The trend was strongest for the cancers suspected to be smoke related and not for those clearly smoke related, which indicates that different smoking prevalence cannot explain the significant trend (last column table 3 ). Interesting is also that the trend in cancers unrelated to smoking is identical with the overall trend in the last column of table 3, indicating that unrelated cancers alone decide the overall trend because of their dominance ( $74 \%$ of all cancers). Hence, remaining confounding by smoking is unlikely to explain the trend in the last column of table 3 .

As cancer data were available for the cohort in 1986-1987, before any effect of the fallout from the Chernobyl accident could be expected, it was possible to calculate an underlying time trend in the further step of the analyses. However, because of aging of the cohort, it was necessary to restrict these comparisons to 5-59 years of age. Between 1986 to 1987 and the follow up period 1988 to 1996, an incidence difference of 30.3 per 100000 person years was found in the reference category - that is, underlying time trend or secular trend (table 5). By the cohort definition, those who got cancer and also died from it within the period 1986-1987 were not enrolled, making the cancer incidence by exposure category slightly lower in that time period, but not affecting the relative comparisons over the categories. As we adjusted for age in table 5, any age related difference in the cancer panorama cannot explain the results in 1986 to 1996.

Radiosensitive neoplasms with assumed short latencies like leukaemia and thyroid cancer are of particular interest. Acute lymphatic leukaemia, acute myeloid leukaemia, and chronic myeloid leukaemia (ICD 7 204.0, 205.0, 205.1) were combined, resulting in a total of 328 cases, 193, men and 135 women, diagnosed during the follow up period. For a similar analysis as in table 5, 250 leukaemia cases aged 5-59 years were available. Because of few cases the three highest

Table 3 Mantel-Haenszel weighted total cancer incidence rate ratio (MH-IRR) adjusted for various determinants with $95 \%$ confidence intervals in parentheses and excess relative risk per $100 \mathrm{kBq} / \mathrm{m}^{2}$ by adjustment column

\begin{tabular}{|c|c|c|c|c|c|c|c|}
\hline \multirow[b]{2}{*}{$\begin{array}{l}\text { Exposure } \mathrm{kBq} \\
\mathrm{Cs}-137 / \mathrm{m}^{2}\end{array}$} & \multirow[b]{2}{*}{$\begin{array}{l}\text { Incidence per } 100 \\
000 \text { person years }\end{array}$} & \multicolumn{6}{|l|}{ MH-IRR adjusted by } \\
\hline & & Age & Age+density & Age $+\mathrm{H}$-region & $\begin{array}{l}\text { Age+lung cancer } \\
\text { incidence as proxy }\end{array}$ & $\begin{array}{l}\text { Age + all cancer incidence } \\
1986-87 \text { as proxy }\end{array}$ & All† \\
\hline$<3$ & 210.3 & 1.00 (reference) & 1.00 (reference) & 1.00 (reference) & 1.00 (reference) & 1.00 (reference) & 1.00 (reference) \\
\hline $3-29$ & 222.1 & 1.09 (1.05 to 1.13$)$ & 1.08 (1.04 to 1.12 ) & $1.07(1.03$ to 1.11$)$ & 1.09 (1.05 to 1.13$)$ & $1.08(1.04$ to 1.12$)$ & $1.05(0.99$ to 1.11$)$ \\
\hline $30-39$ & 223.6 & 1.05 (0.99 to 1.11$)$ & 1.07 (1.01 to 1.13$)$ & $1.04(0.98$ to 1.10$)$ & 1.05 (0.99 to 1.11$)$ & $1.04(0.98$ to 1.10$)$ & 1.03 (0.95 to 1.12$)$ \\
\hline $40-59$ & 248.8 & 1.11 (1.06 to 1.17$)$ & 1.08 (1.03 to 1.14$)$ & 1.09 (1.04 to 1.15$)$ & 1.11 (1.06 to 1.17$)$ & $1.10(1.04$ to 1.16$)$ & $1.08(0.94$ to 1.23$)$ \\
\hline $60-79$ & 209.5 & $0.98(0.88$ to 1.08$)$ & $1.01(0.91$ to 1.13$)$ & $0.99(0.89$ to 1.10$)$ & $0.97(0.88$ to 1.08$)$ & $0.97(0.87$ to 1.08$)$ & $1.10(0.89$ to 1.34$)$ \\
\hline $80-120$ & 244.4 & $1.23(1.11$ to 1.38$)$ & 1.18 (1.05 to 1.33$)$ & $1.20(1.06$ to 1.34$)$ & 1.21 (1.08 to 1.36$)$ & 1.22 (1.08 to 1.37$)$ & $1.21(0.98$ to 1.49$) \ddagger$ \\
\hline \multicolumn{2}{|c|}{$\begin{array}{l}\text { Excess relative risk by column per } \\
100 \mathrm{kBq} / \mathrm{m}^{2} \text { (Poisson regression) }\end{array}$} & 0.16 (0.08 to 0.24$)$ & $0.13(0.05$ to 0.21$)$ & $0.12(0.04$ to 0.20$)$ & $0.14(0.06$ to 0.22$)$ & $0.15(0.07$ to 0.24$)$ & $0.11(0.03$ to 0.20$)$ \\
\hline
\end{tabular}


Table 4 Mantel-Haenszel weighted incidence rate ratio (MH-IRR) for cancers clearly related to tobacco smoking $(n=4087)$, for cancers suspected to be related to tobacco smoking ( $n=1585)$, and for cancers unrelated to tobacco smoking $(n=16737)$ with $95 \%$ confidence intervals in parentheses and excess relative risk per $100 \mathrm{kBq} / \mathrm{m}^{2}$ by column

\begin{tabular}{|c|c|c|c|c|c|c|}
\hline \multirow{2}{*}{$\begin{array}{l}\text { Exposure } \mathrm{kBq} \\
\mathrm{Cs}-137 / \mathrm{m}^{2}\end{array}$} & \multicolumn{2}{|c|}{$\begin{array}{l}\text { Cancers clearly related to smoking* MH-IRR } \\
\text { adjusted by }\end{array}$} & \multicolumn{2}{|c|}{$\begin{array}{l}\text { Cancers suspected to be related to smokingt } \\
\text { MH-IRR adjusted by }\end{array}$} & \multicolumn{2}{|c|}{$\begin{array}{l}\text { Cancers unrelated to smoking } \ddagger \text { MH-IRR } \\
\text { adjusted by }\end{array}$} \\
\hline & Age & Age $+\operatorname{sex}$ & Age & Age+sex & Age & Age+sex \\
\hline$<3$ & 1.00 (reference) & 1.00 (reference) & 1.00 (reference) & 1.00 (reference) & 1.00 (reference) & 1.00 (reference) \\
\hline $3-29$ & $1.06(0.98$ to 1.14$)$ & $1.06(0.98$ to 1.14$)$ & 0.95 (0.84 to 1.07$)$ & 0.95 (0.84 to 1.07$)$ & $1.10(1.06$ to 1.15$)$ & $1.10(1.06$ to 1.15$)$ \\
\hline $30-39$ & $1.04(0.92$ to 1.18$)$ & $1.04(0.92$ to 1.18$)$ & $1.15(0.95$ to 1.38$)$ & $1.15(0.95$ to 1.38$)$ & $1.04(0.98$ to 1.11$)$ & $1.04(0.98$ to 1.12$)$ \\
\hline $40-59$ & $1.22(1.10$ to 1.36$)$ & $1.23(1.11$ to 1.36$)$ & $1.12(0.95$ to 1.32$)$ & $1.12(0.95$ to 1.32$)$ & 1.09 (1.04 to 1.16$)$ & 1.09 (1.03 to 1.15$)$ \\
\hline $60-79$ & $1.00(0.79$ to 1.27$)$ & $1.00(0.79$ to 1.27$)$ & $1.06(0.74$ to 1.52$)$ & $1.06(0.74$ to 1.52$)$ & 0.95 (0.85 to 1.08$)$ & 0.95 (0.84 to 1.08$)$ \\
\hline $80-120$ & 1.23 (0.96 to 1.59$)$ & $1.23(0.96$ to 1.59$)$ & 1.71 (1.23 to 2.39$)$ & 1.71 (1.23 to 2.39$)$ & 1.18 (1.04 to 1.34$)$ & 1.18 (1.04 to 1.34$)$ \\
\hline $\begin{array}{l}\text { Excess relative risk by } \\
\text { column per } 100 \mathrm{kBq} / \mathrm{m}^{2} \\
\text { (Poisson regression) }\end{array}$ & $20.28(0.10$ to 0.50$)$ & & $0.47(0.16$ to 0.88$)$ & & $0.11(0.02$ to 0.20$)$ & \\
\hline
\end{tabular}

exposure categories were merged. The standardised incidence rate differences and ratios were unstable but somewhat higher than the reference category (table 6).

There were 67 thyroid cancer cases (ICD 7 194) diagnosed in men and 185 in women during the follow up period, with none in children 0-9 years. A similar analysis as for leukaemia was done, including 211 cases in the age of 5-59 years. Again because of the few cases the three highest exposure categories were merged. The standardised incidence rate differences and ratios were unstable and did not show any obvious increase in the higher exposure categories (table 7).

\section{DISCUSSION}

Unless simply representing a chance phenomenon, the findings in our study are somewhat unexpected indicating a possible cancer effect of the Chernobyl fallout in north Sweden despite a short latency period and low degree of exposure. This would also be the first study suggesting a possible increase in total cancer incidence after the Chernobyl accident outside the former Soviet Union, ${ }^{13}$ let alone only a marginally increased risk. Based on the incidence rate ratios in the last column of table 3, the aetiological fractions can be calculated. Subsequently the total number of incident cancer cases related to the Chernobyl accident in the seven counties of Sweden can formally be estimated as 849 during the follow up to 1996. However, no less than 494 of these cases are derived from the second category 3-29 kiloBecquerel $/ \mathrm{m}^{2}$. A slightly different classification of the reference category would therefore dramatically influence the number of exposure related cancer cases. On the other hand, the risk estimate in the highest exposure category had to be calculated with the second category as reference, thus making both the risk estimate and the aetiological fraction conservative. Using the estimated collective dose in Sweden of about 6000 manSievert during 50 years, ${ }^{7}$ and the risk estimates given by the International Commission on Radiological Protection, ${ }^{14}$ the number of expected extra cancer deaths has been calculated to be $300 .{ }^{15}$

Given a true effect, our study shows that the risk from low dose irradiation might come earlier and be slightly higher than predicted by the International Commission on Radiological Protection estimates, let alone random variation and other uncertainty in our study about the calculated number of extra cases. The official risk estimate relies to a great extent on the follow up of the atomic bomb survivors in Hiroshima and Nagasaki, but has been questioned as the cohort was created five years after the explosions and therefore ignoring early cases. ${ }^{16}$

A short latency period like in our study has been seen in other epidemiological studies on ionising radiation. ${ }^{17-20}$ Recent evaluations of radon progeny exposure and lung cancer has also indicated that the comparatively recent exposure might have the stronger effect according to the analytical models applied. ${ }^{21}$ Our findings of an increase of total cancer incidence in Sweden soon after the Chernobyl accident is therefore not a unique finding, but we have not been able to detect any specific cancer site responsible for our findings. An interpretation could therefore be that the ionising radiation might exert a late stage general promoting effect on cancer.

Confounding effects are exerted by independent risk factors associated with the exposure. A crucial question is therefore if some unidentified risk factor(s) for cancer could have caused confounding by operating parallel to our exposure classification or if some other kind of undetected bias

Table 5 Age standardised total cancer incidence per 100000 person years ( $10^{5}$ py) in ages $5-59$ years, directly standardised incidence rate ratios (SIRR), and standardised incidence rate differences per 100000 person years (SIRD) with $95 \%$ confidence intervals $(95 \% \mathrm{Cl})$. European population restricted to ages 5-59 years is used as the standard

\begin{tabular}{|c|c|c|c|c|c|c|c|}
\hline \multirow[b]{2}{*}{$\begin{array}{l}\text { Exposure kBq } \\
\mathrm{Cs}-137 / \mathrm{m}^{2}\end{array}$} & \multicolumn{3}{|c|}{ 1986-1987 } & \multicolumn{3}{|c|}{ 1988-1996 } & \multirow{2}{*}{$\begin{array}{l}1988-1996 \text { minus } \\
1986-1987 \\
\text { SIRD per } 10^{5} \text { py } 195 \% \mathrm{CI}\end{array}$} \\
\hline & Cases (n) & $\begin{array}{l}\text { Incidence per } \\
10^{5} \text { py }\end{array}$ & SIRR $(95 \% \mathrm{Cl})$ & Cases (n) & $\begin{array}{l}\text { Incidence per } \\
10^{5} \text { py }\end{array}$ & SIRR $(95 \% \mathrm{CI})$ & \\
\hline$<3$ & 712 & 106.3 & $\begin{array}{l}1.00 \text { (reference for } \\
\text { all SIRR) }\end{array}$ & 4181 & 136.6 & $1.29(1.18$ to 1.40$)$ & 30.3 (25.5 to 35.2$)$ \\
\hline $3-29$ & 1024 & 107.3 & $1.01(0.91$ to 1.12$)$ & 6402 & 144.1 & $1.36(1.25$ to 1.47$)$ & 36.8 (32.6 to 41.0 ) \\
\hline $30-39$ & 175 & 101.2 & $0.95(0.80$ to 1.13$)$ & 1130 & 143.2 & $1.35(1.22$ to 1.49$)$ & 42.0 (33.0 to 51.0$)$ \\
\hline $40-59$ & 254 & 103.1 & 0.97 (0.84 to 1.13$)$ & 1623 & 148.9 & $1.40(1.28$ to 1.54$)$ & 45.8 (37.9 to 53.4$)$ \\
\hline $60-79$ & 36 & 81.7 & 0.77 (0.54 to 1.08 ) & 252 & 131.8 & 1.24 (1.07 to 1.44$)$ & 50.1 (29.4 to 70.8$)$ \\
\hline $80-120$ & 32 & 109.4 & $1.03(0.71$ to 1.48$)$ & 235 & 165.8 & 1.56 (1.34 to 1.82$)$ & 56.4 (33.9 to 78.9$)$ \\
\hline Total & 2233 & & & 13823 & & & \\
\hline
\end{tabular}


Table 6 Age standardised leukaemia (ICD $7204.0,205.0,205.1)$ incidence per 100000 person years $\left(10^{5}\right.$ py) in ages $5-$ 59 years, directly standardised incidence rate ratios (SIRR), and standardised incidence rate differences per 100000 person years (SIRD) with $95 \%$ confidence intervals $(95 \% \mathrm{Cl})$. European population restricted to ages $5-59$ years is used as the standard

\begin{tabular}{|c|c|c|c|c|c|c|c|}
\hline \multirow[b]{2}{*}{$\begin{array}{l}\text { Exposure } \mathrm{kBq} \\
\mathrm{Cs}-137 / \mathrm{m}^{2}\end{array}$} & \multicolumn{3}{|c|}{ 1986-1987 } & \multicolumn{3}{|c|}{ 1988-1996 } & \multirow{2}{*}{$\begin{array}{l}1988-1996 \text { minus } \\
1986-1987 \\
\text { SIRD per } 10^{5} \text { py } \\
(95 \% \mathrm{Cl})\end{array}$} \\
\hline & Cases (n) & $\begin{array}{l}\text { Incidence per } \\
10^{5} \mathrm{py}\end{array}$ & SIRR $(95 \% \mathrm{Cl})$ & Cases (n) & $\begin{array}{l}\text { Incidence per } \\
10^{5} \mathrm{py}\end{array}$ & SIRR $(95 \% \mathrm{Cl})$ & \\
\hline$<3$ & 14 & 2.07 & $\begin{array}{l}1.00 \text { (reference for } \\
\text { all SIRR) }\end{array}$ & 78 & 2.63 & 1.27 (0.71 to 2.25$)$ & $0.56(0.12$ to 1.00$)$ \\
\hline $3-29$ & 20 & 2.14 & $1.03(0.52$ to 2.05$)$ & 119 & 2.86 & $1.38(0.79$ to 2.41$)$ & $0.72(0.31$ to 1.13$)$ \\
\hline $30-39$ & 1 & 0.66 & $0.32(0.41$ to 2.43$)$ & 18 & 2.46 & $1.19(0.58$ to 2.40$)$ & $1.80(0.25$ to 3.49$)$ \\
\hline $40-120$ & 5 & 1.68 & 0.81 (0.29 to 2.26$)$ & 35 & 2.64 & 1.27 (0.68 to 2.38$)$ & 0.96 (0.57 to 1.34$)$ \\
\hline
\end{tabular}

could have created the increased risks. In general, confounding effects tend to be rather weak even if comparatively more important when dealing with slightly increased risks. ${ }^{22}$ To maximise adjustment for confounding we sought those assessable risk factors that were strong and weakly associated with the caesium-137 categories or weak but strongly associated in this respect. As there was little effect of the various adjustments undertaken it is less likely that unknown confounding factors could have strongly influenced the risk estimates found. It would also be remarkable if any such factor could have caused a dose-response pattern, let alone the slightly increased risks found in our study. However, the observed dose-response pattern to some extent depends on the highest exposure category, and consequently the interpretation must be cautious with regard to causality. A concern could be that the period 1986-1987 is too short for assessing a background cancer incidence in the fallout area, but using a longer time period before the accident instead might not be relevant for the follow up period. As shown in table 5, cancer incidence during 1986-1987 does not show an association with the exposure categories, in contrast with the trend seen for 1988-1996.

Although this study is of the cohort design, it has also some of the weaknesses of a correlation (or ecological) study-that is, the lack of individual data on potential confounders. However, our study has some advantages over the previous ones, ${ }^{1-5}$ as the assessment of exposure is reasonably proper and because of the inclusion criterion of subjects living in the same parish for two years. Furthermore, small geographical areas (parishes) could be used for assessing exposure. The areas representing various exposure levels are scattered and therefore unlikely to reflect any simple geographical gradients in cancer incidence. In contrast with the earlier studies, ours also includes an adult population. The achieved external dose for the defined two years when the cohort members lived in the same parish, is a considerable part of the lifetime exposure from the Chernobyl accident. An even better exposure assessment would have been obtained if we could have traced the addresses of each person also during the follow up period. However, most probably the majority of the population has continued to live in the same parish throughout the duration of the study.

A larger problem is that the exposure assessment was based on the ground deposition of caesium-137 from the Chernobyl accident, not taking into account any internal dose contribution through food and inhalation. This is especially important in regions with comparatively low ground deposition where a high intake of wild berries, mushrooms, game meat, etc, will give a higher internal than external dose from caesium-137. Restrictions in food intake because of governmental regulation are likely to have led to lower doses, especially in higher exposed areas, hence lowered the radiation induced cancer risks for the population in comparison with what would otherwise have prevailed. Therefore, as we relied on deposition maps it has not been possible to estimate the individual dose, nor to give details on uncertainties in the dose estimates.

We have not been able to control for radon or indoor/ outdoor gamma exposure. If anything, this radiation, as unrelated to the fallout from the Chernobyl accident, would have obfuscated an effect regarding leukaemia in our study as previous studies have indicated a leukaemogenic effect from indoor gamma radiation. ${ }^{23} 24$

Using a conversion factor for the external effective dose from the Chernobyl fallout for the two year period 1986-1987, ${ }^{82}$ one obtains an estimation of an about 7-10 $\mathrm{mSv}$ dose in the highest exposure category. Because of the uncertainties in the indi4vidual dose assessment we have chosen to express the excess relative risk per $100 \mathrm{kiloBecquerel} / \mathrm{m}^{2}$, making it possible to compare the risk with future similar epidemiological studies.

Table 7 Age standardised thyroid cancer (ICD 7 194) incidence per 100000 person years (10 $0^{5}$ py) in ages 5-59 years, directly standardised incidence rate ratios (SIRR), and standardised incidence rate differences per 100000 person years (SIRD) with $95 \%$ confidence intervals $(95 \% \mathrm{CI})$. European population restricted to ages 5-59 years is used as the standard

\begin{tabular}{|c|c|c|c|c|c|c|c|}
\hline \multirow[b]{2}{*}{$\begin{array}{l}\text { Exposure kBq } \\
\mathrm{Cs}^{-}-137 / \mathrm{m}^{2}\end{array}$} & \multicolumn{3}{|c|}{ 1986-1987 } & \multicolumn{3}{|c|}{ 1988-1996 } & \multirow{2}{*}{$\begin{array}{l}1988-1996 \text { minus } 1986- \\
1987 \\
\text { SIRD per } 10^{5} \text { py }(95 \% \mathrm{CI})\end{array}$} \\
\hline & Cases (n) & $\begin{array}{l}\text { Incidence per } \\
10^{5} \mathrm{py}\end{array}$ & SIRR $(95 \% \mathrm{CI})$ & Cases $(\mathbf{n})$ & $\begin{array}{l}\text { Incidence per } \\
10^{5} \mathrm{py}\end{array}$ & SIRR $(95 \% \mathrm{CI})$ & \\
\hline$<3$ & 19 & 2.67 & $\begin{array}{l}1.00 \text { (reference for } \\
\text { all SIRR) }\end{array}$ & 68 & 2.23 & $0.83(0.50$ to 1.40$)$ & $-0.44(-0.90$ to 0.02$)$ \\
\hline 3-29 & 24 & 2.43 & 0.91 (0.49 to 1.67$)$ & 103 & 2.32 & $0.87(0.53$ to 1.43$)$ & $-0.11(-0.51$ to 0.30$)$ \\
\hline $30-39$ & 4 & 2.30 & 0.86 (0.29 to 2.56$)$ & 18 & 2.33 & $0.87(0.45$ to 1.68$)$ & $0.03(-0.53$ to 0.60$)$ \\
\hline $40-120$ & 6 & 1.84 & $0.69(0.27$ to 1.74$)$ & 22 & 1.55 & $0.58(0.31$ to 1.08$)$ & $-0.29(-0.93$ to 0.35$)$ \\
\hline Total & 53 & & & 211 & & & \\
\hline
\end{tabular}


Smoking is a primary concern in all cancer epidemiology, but any stronger association of smoking frequencies with the exposure categories is unlikely and there is no practical way of obtaining individual smoking data for a cohort of our size. Another aspect is that smoking associated cancers represent only a minor contribution to the total cancer incidence (table 4). Furthermore, an adjustment for smoking was undertaken through the use of lung cancer incidence as a proxy for smoking. It seems very unlikely, therefore, that smoking or any other related confounding factor (lifestyle or other) should be so closely associated with the distribution of the fallout from the accident as to explain the dose-response pattern seen in our study. Instead, our lung cancer adjustment may be an over-adjustment rather than the opposite, although an effect can be seen. Using a cancer rate as a proxy confounder obviously requires that the exposure under study is only marginally contributing to that cancer rate. This condition is clearly fulfilled in our study.

Population density seems to be a risk factor for cancer in our study, as in another investigation, ${ }^{26}$ and exerted confounding in the exposure categories. By using two different population density classifications we could adjust for some residual confounding left out from either of them. In contrast with our own classification, the homogeneity regions take into account commuting from sparsely populated parishes to work in a nearby city.

The interpretation of the finding regarding thyroid cancer incidence is difficult because of the unclear dose-response and the lack of any increased risk in younger ages. However, the iodine status of the Swedish population is good, making the children less sensitive, and locally produced food plays a limited part in the areas with high fallout in Sweden. It is also possible that the radiation levels were too low in Sweden to cause an increased risk of thyroid cancer.

We were unable to detect any clear increase in leukaemia during the follow up. Similarly, not even in the most heavily polluted areas in the former Soviet Union, any clear increase of leukaemia has been observed as yet. Nor did we find any such tendencies in our earlier study on childhood leukaemia in north Sweden. ${ }^{5}$ On the other hand, it has been suggested that the established association between ionising radiation and leukaemia is unique for the comparatively high, but short time dose exposure after the atomic bomb explosions and not applicable in low dose studies. ${ }^{16}$

The follow up period is still rather short in our study and a longer study period is necessary for any more definitive conclusions about a causal relation between the radioactive fallout in Sweden and the cancer incidence. Should we be observing some late stage promotion effect on ongoing cancer development in the population, there might even follow a decrease in the cancer incidence with an about normal cumulative incidence over a longer period of time. This remark, however, is a speculative conjecture to be investigated in future studies.

\section{ACKNOWLEDGEMENTS}

The authors want to acknowledge Martin Eriksson and Sören Jakobsson, Department of Public Health Medicine, Gävleborg County Council, Central Hospital, Gävle, Sweden for their contribution in classifying the parishes for this study. We also want to thank Peter Lindgren, Division of Occupational and Environmental Medicine, Department of Molecular and Clinical Medicine, Faculty of Health Sciences, Linköping University, Sweden for preparing the map. Finally, Francesco Forastiere, Italy, Kyle Steenland, US and Dina Schreinemachers, US gave some valuable comments on the manuscript.

\section{Authors' affiliations}

M Tondel, P Hialmarsson, $\mathrm{O}$ Axelson, Division of Occupational and Environmental Medicine, Department of Molecular and Clinical
Medicine, Faculty of Health Sciences, Linköping University, Linköping, Sweden

L Hardell, Department of Oncology, Örebro University Hospital, Örebro, Sweden

G Carlsson, Department of Health Policy, Västernorrland County Council, Härnösand, Sweden

Funding: the study was supported by a grant from Jenny Nordqvist Minnesfond.

Conflicts of interest: none declared.

It is with regret that we report that Olav Axelson died before the publication of this paper.

\section{REFERENCES}

1 Auvinen A, Hakama $M$, Arvela $\mathrm{H}$, et al. Fallout from Chernobyl and incidence of childhood leukaemia in Finland, 1976-92. BMJ 1994;309:151-4.

2 Hjalmars U, Kulldorff M, Gustafsson G. Risk of acute childhood leukaemia in Sweden after the Chernobyl reactor accident. Swedish Child Leukaemia Group. BMJ 1994;309:154-7.

3 Parkin DM, Clayton D, Black RJ, et al. Childhood leukaemia in Europe after Chernobyl: 5 year follow-up. Br J Cancer 1996;73:1006-12.

4 Petridou E, Proukakis C, Tong D, et al. Trends and geographical distribution of childhood leukemia in Greece in relation to the Chernobyl accident. Scand J Soc Med 1994;22:127-31.

5 Tondel M, Carlsson G, Hardell L, et al. Incidence of neoplasms in ages 0-19 y in parts of Sweden with high 137Cs fallout after the Chernobyl accident. Health Physics 1996:71:947-50.

6 World Health Organisation. Health consequences of the Chernobyl accident Results of the IPHECA pilot projects and related national programmes, summary report. Geneva: WHO, 1995.

7 Mattsson S, Moberg L. Fallout from Chernobyl and atmospheric nuclear weapons tests-Chernobyl in perspective. In: Moberg L, ed. The Chernoby fallout in Sweden-results from a research programme on environmental radiology. Stockholm: Swedish Radiation Protection Institute, 1991:591-627.

8 Edvarson K. External doses in Sweden from the Chernobyl fallout. In: Moberg L, ed. The Chernobyl fallout in Sweden-results from a research programme on environmental radiology. Stockholm: Swedish Radiation Protection Institute, 1991:527-45.

9 Tondel $M$, Axelson $O$. Concerns about privacy in research may be exaggerated. BMJ 1999;319:706-7.

10 Statistics Sweden. Numerical codes by region for various Swedish subdivisions, January 1, 1998. Örebro: SCB, 1998.

11 Dreyer L, Winther JF, Pukkala E, et al. Avoidable cancers in the Nordic countries. Tobacco smoking. APMIS 1997;76(suppl):9-47.

12 World Health Organisation. International Agency for Research on Cancer, International Association of Cancer Registries. Cancer incidence in five continents, vol 3, IARC scientific publications no 15. Lyon: IARC, 1976

13 Sali D, Cardis E, Sztanyik L, et al. Cancer consequences of the Chernobyl accident in Europe outside the former USSR: a review. Int J Cancer 1996:67:343-52.

14 The International Commission on Radiological Protection. 1990 Recommendations of the International Commission on Radiological Protection, ICRP Publication 60. Oxford: Pergamon Press, 1990.

15 Moberg L, Reizenstein P. Health effects in Sweden of the Chernobyl accident. [In Swedish]. Nord Med 1993;108:117-20.

16 Stewart AM, Kneale GW. A-bomb survivors: factors that may lead to a re assessment of the radiation hazard. Int J Epidemiol 2000;29:708-14.

17 Hornung RW, Meinhardt TJ. Quantitative risk assessment of lung cancer in U.S. uranium miners. Health Physics 1987;52:417-30.

18 Langholz B, Thomas D, Xiang A, et al. Latency analysis in epidemiological studies of occupational exposures: application to the Colorado Plateau uranium miners cohort. Am J Ind Med 1999;35:246-56.

19 Wing S, Richardson D, Armstrong D, et al. A reevaluation of cancer incidence near the Three Mile Island nuclear plant: the collision of evidence and assumptions. Environ Health Perspect 1997; 105:52-7.

20 Talbott EO, Youk AO, McHugh-Pemu KP, et al. Long-term follow-up of the residents of the Three Mile Island accident area 1979-1998. Environ Health Perspect 2003;111:341-8.

21 Committee on Health Risks of Exposure to Radon (BEIRVI), Board on Radiation Effects Research, Commission on Life Sciences, National Research Council. Health effects of exposure to radon. Washington: National Academy Press, 1999.

22 Axelson O, Steenland K. Indirect methods of assessing the effects of tobacco use in occupational studies. Am J Ind Med 1988;13:105-18.

23 Flodin U, Fredriksson M, Persson B, et al: Acute myeloid leukemia and background radiation in an expanded case-referent study. Arch Environ Health 1990;45:364-6.

24 Axelson O, Fredrikson M, Akerblom G, et al. Leukemia in childhood and adolescence and exposure to ionizing radiation in homes built from uraniumcontaining alum shale concrete. Epidemiology 2002;13:146-50.

25 Edvarson K. Fallout over Sweden from the Chernobyl accident. In: Moberg L, ed. The Chernobyl fallout in Sweden - results from a research programme on environmental radiology. Stockholm: Swedish Radiation Protection Institute, 1991:47-65.

26 Schouten LJ, Meijer H, Huveneers JA, et al. Urban-rural differences in cancer incidence in the Netherlands 1989-1991. Int J Epidemiol 1996;25:729-36. 